\title{
Are small case-loads beautiful in severe mental
}

\section{illness? ${ }^{\dagger}$}

\author{
PETER TYRER
}

A small case-load is becoming one of the shibboleths of community psychiatry. The paper by Burns et al (2000, this issue) focuses on this matter with a comparison of two models of service delivery in recurrent psychotic illness: intensive and standard case management. The main difference between these two models was the case-load per keyworker; those in intensive case management (ICM) had no more than 15 per keyworker whereas standard case management (SCM) had case-loads of between 30 and 35 . In addition, however, those in the intensive management service also received a brief course of training in the Boulder Community Support System (CSS) model of care; this shows similarities with assertive community treatment $(\mathrm{ACT})$ practised elsewhere in the USA (Stein \& Santos, 1998, p. 33).

The results of the study may at first sight be unexceptional. Those allocated in the randomised trial to ICM received more input from all sources, both directly and indirectly, than those allocated to SCM. This was particularly marked for face-to-face contacts with the patients concerned and even more so for failed face-to-face contacts, most of which were attempted at the patient's home. The significance of the findings becomes greater when one considers other findings from the UK700 Group and the general policy context of ACT. The main question the findings pose is why the greater frequency of contact in ICM was not translated into any clinical improvement with regard to either the primary outcome (duration of in-patient psychiatric treatment during the study) or a range of secondary outcomes, including the specific one that improvement with ICM might be more effective in those of AfricanCaribbean ethnicity (UK700 Group, 1999a). This has been the subject of recent correspondence in the Journal about another study that showed no benefit of ICM and, for some variables, showed superior benefit with SCM (Thornicroft et al, 1998; Wykes

†See pp. 427-433, this issue. et al, 1998). The contradiction between the findings in these studies and those from other parts of the world, notably Australia and the USA, has led to questions about fidelity to the model, possible differences in core services in the countries concerned and, as the authors argue in their paper, the possibility that the care model may have been followed faithfully but was not necessarily using successful (evidence-based) interventions.

\section{FIDELITY TO THE MODEL}

It is difficult to be certain what constitutes the essential components of ICM. Assertive community treatment comprises six essential features: case-loads of no fewer than 8 and no more than 12 per keyworker, an integrated team structure with at least three professional disciplines, no more than $20 \%$ of staff part-time, 24-hour availability, team autonomy and (an important consideration) part-time psychiatrist input only (Stein \& Santos, 1998, pp. 64-65). Intensive case management in Burns et al's study did not satisfy all these requirements. The upper case-load was slightly higher than allowed in ACT, none of the teams operated a 24hour service (the services outside normal hours were provided equivalently for standard and intensive teams) and frequency of contact, averaging once every 9 days in the intensive team, was much less than ACT and CSS studies recommend (Stein \& Santos, 1998).

However, some of these differences may be related to different policies in different countries. Home treatment and depot injections are more common in the UK than in the USA. In ACT and CSS teams in the USA it is commonplace for patients to receive oral medication and to attend daily for administration and monitoring purposes and this makes it much easier for the team to monitor than if they regularly saw such patients at home. The presence of 24-hour cover is also not as important in the UK as in the USA. Because there is often no real health cover available for these patients in the USA it is easy to see why it was necessary to set up a telephone contact system. However, as there is comprehensive 24-hour cover in almost all areas of the UK for psychiatric emergencies, it is not often justified to set up separate cover for an intensive team.

Taken together, it does not look as if the differences between ICM in the UK700 study and elsewhere are sufficient to explain the negative findings of the intensive model. It is also argued that a good assertive team takes time to establish and that this would apply to ICM also. In the UK700 study, three of the four centres involved new teams set up specifically for the purposes of the research and it could be argued that these had not been sufficiently well integrated to provide good intensive care. However, this criticism is to some extent countered by the fact that the team with the most ICM experience and a proven record of success, that of St George's Hospital (Burns et al, 1993a,b), also showed no superiority over SCM despite having a greater frequency of face-to-face contact than the other two intensive teams.

\section{DIFFERENCES IN STANDARD CARE}

Unlike drug treatment, psychosocial treatments have a habit of taking on the good elements of fellow treatment approaches quietly, almost by stealth, and in the UK we have long had a pragmatic approach to community care which could be called ACC, or assertive community creep. Although the proponents of assertive treatment argue that it has revolutionised the care of the severely mentally ill in the USA, it holds no patent on its key elements and many of them have been used to good effect long before ACT and ICM became fashionable acronyms. In the UK we have long been aware of the negative aspects of care in state mental institutions (Lomax, 1921) and of the benefits of early intervention and assertive contact with patients at home (MacMillan, 1963; Sainsbury et al, 1966). The UK also did not make the mistake of imitating the experiment of the community mental health centre movement in the USA in the 1960s that really led to the conditions ripe for the birth of ACT, a dearth of satisfactory community services for those with severe mental illness. From the early 1970 s onwards, community mental health teams, often consisting of only two 
disciplines, nurses and psychiatrists, have developed in many countries and, to varying degrees, have quietly taken on the type of service that has been promoted quite aggressively in recent years by the ACT movement.

It is therefore not surprising that comparisons of the new treatment model with a standard model containing some of its key elements are not going to show the same benefits as when the standard treatment contains none of these elements. This is demonstrated by Burns et al (2000, this issue) in their paper, in which the differences between each limb of the psychiatric service are quantitative rather than qualitative in nature. It therefore behoves researchers in future studies of these models to define 'standard' more precisely.

\section{ABSENCE OF EVIDENCE- BASED INTERVENTIONS}

The argument that both ICM and SCM teams might well have delivered the same evidence-based interventions to the patients under their care, accounting for the absence of significant difference between the models, is a powerful one. Additional face-to-face contacts are not therapeutic in themselves, although much of the literature on the subject may imply this. A simple question such as 'Does intensive case management improve compliance with medication?' cannot be answered from most studies comparing these models, and the UK700 study is no exception. We have no evidence that new interventions that have good evidence of their efficacy and durability in psychotic disorders (e.g. Kemp et al, 1996, 1998; Perry et al, 1999; Tarrier et al, 1999) are being used, and these should be compared in future studies rather than all our attention being focused on the management elements of care.

\section{NEGATIVE INFLUENCES OF ICM}

This question is not a heretical one. There must come a point at which persistently striving to keep a patient out of hospital becomes an inappropriate aim, both clinically and economically. Only the most fanatical of community treatment enthusiasts argue that psychiatric beds are unnecessary and no one has successfully achieved a bedless service for the severely mentally ill. It is interesting that the UK700 study demonstrated powerful benefits in favour of ICM compared with SCM for one important

PETER TYRER, FRCPsych, Head, Department of Public Mental Health, Division of Neuroscience and Psychological Medicine, Imperial College School of Medicine, St Mary's Campus, Paterson Centre, 20 South Wharf Road, London W2 IPD

(First received 25 June 2000, accepted I4 July 2000)

group - those with recurrent psychosis and borderline learning disability, who comprise just under one in seven of the total sample (UK700 Group, 1999b). This population shows important differences from those with an IQ within the normal range (Hassiotis et al, 1999) and they may be helped more by this approach because they have greater difficulty in expressing their needs and may require a more assertive approach to all parts of their care. Those within the normal IQ range may find frequent contacts intrusive, particularly if they occur at home, and react adversely. One of the unexpected findings in the main UK700 study (UK700 Group, 1999a) was that those in ICM were significantly more likely to lose contact with their case manager than those in the SCM teams. This is in keeping with the above hypothesis. More needs to be done to ensure better adherence to treatment plans that prevent loss of contact from care, for although contact is the main asset of the Care Programme Approach (Tyrer et al, 1995) it could go much further. It may require lessened focus on face-to-face contacts; in the UK700 study a marked reduction in the frequency of these was seen over time in the St Mary's team that was successfully transferred to a liaison role (Weaver, 2000).

Against this raft of negative evidence it is surprising that the UK Government continues to promote assertive outreach (an odd term that does not have a clear definition) as the recommended way forward for the community care of those with severe mental illness (Department of Health, 1998, 1999). The good news that should be promoted across the country is that good sectorised community mental health teams, despite the battering they often unfairly receive in government inquiries, constitute a robust method of delivering good-quality care and that it is these, rather than imported models of service delivery, that should be the focus of our praise.

\section{REFERENCES}

Burns, T., Beadsmoore, A., Bhat, A. V., et al (1993a) A controlled trial of home-based acute psychiatric services. I: Clinical and social outcome. British Journal of Psychiatry, 163, 49-54.
_ , Raftery, J., Beadsmoore, A., et al (1993b) A controlled trial of home-based acute psychiatric services. II: Treatment patterns and costs. British Journal of Psychiatry, 163, 55-61.

_ , Fiander, M., Kent, A., et al (2000) Effects of caseload size on the process of care of patients with severe psychotic illness. Report from the UK700 trial. British Journal of Psychiatry, 177, 427-433.

Department of Health (1998) A First Class Service: Quality in the New NHS. London: Department of Health. - (1999) A National Service Framework for Mental Health. London: Department of Health.

Hassiotis, A., Ukoumunne, O., Tyrer, P., et al (1999) Prevalence and characteristics of patients with severe mental illness and borderline intellectual functioning. Report from the UK700 randomised controlled trial of case management. British Journal of Psychiatry, 175, 135-140.

Kemp, R., Hayward, P., Applewhaite, G., et al (1996) Compliance therapy in psychotic patients: randomised controlled trial. British Medical Journal, 312, 345-349.

_ , Kirov, G., Everitt, B., et al (1998) Randomised controlled trial of compliance therapy. 18-month followup. British journal of Psychiatry, 172, 4I3-419.

Lomax, M. (1921) The Experiences of an Asylum Doctor, with Suggestions for Asylum and Lunacy Law. London: George Allen \& Unwin.

MacMillan, D. (1963) Recent developments in community mental health. Lancet, i, 567-57l.

Perry, A., Tarrier, N., Morriss, R., et al (1999) Randomised controlled trial of efficacy of teaching patients with bipolar disorder to identify early symptoms of relapse and obtain treatment. British Medical Journal, 318, 149-153.

Sainsbury, P.,Walk, D. \& Grad, J. (1966) Evaluating the Graylingwell Hospital community psychiatric service in Chichester. Millbank Memorial Fund Quarterly, 44, 243-245.

Stein, L. I. \& Santos, A. B. (1998) Assertive Community Treatment of Persons with Severe Mental Illness. London and New York: W.W. Norton.

Tarrier, N., Wittkowski, A., Kinney, C., et al (1999) Durability of the effects of cognitive-behavioural therapy in the treatment of chronic schizophrenia: 12-month follow-up. British Journal of Psychiatry, 174, 500-504.

Thornicroft, G., Wykes, T., Holloway, F., et al (1998) From efficacy to effectiveness in community mental health services. PRiSM Psychosis Study 10. British Journal of Psychiatry, 173, 423-427.

Tyrer, P., Morgan, J., Van Horn, E., et al (1995) A randomised controlled study of close monitoring of vulnerable psychiatric patients. Lancet, 345, 756-759. UK700 Group (1999a) Intensive versus standard case management for severe psychotic illness: a randomised trial. Lancet, 33, 2185-2189.

- (1999b) Intensive case management for psychotic patients with borderline intelligence. Lancet, 354, 999-1000.

Weaver, T. (2000) Longitudinal study of the implementation of case management for severe mental illness. PhD thesis, University of London.

Wykes, T., Leese, M., Taylor, R., et al (1998) Effects of community services on disability and symptoms. PRiSM Psychosis Study 4. British Journal of Psychiatry, 173, 385-390. 